\title{
Exploring the assumptions underlying genetic variation in host nematode resistance
} (Open Access publication)

\author{
Andrea Beate DoESCHL-WILSON ${ }^{1 *}$, Dimitrios VAGENAS ${ }^{2}$, \\ Ilias KYRIAZAKIS ${ }^{2,3}$, Stephen Christopher BISHOP ${ }^{4}$ \\ ${ }^{1}$ Sustainable Livestock Systems, Scottish Agricultural College, West Mains Road, \\ Edinburgh, EH9 3JG, UK \\ ${ }^{2}$ Animal Health and Nutrition Department, Scottish Agricultural College, West Mains Road, \\ Edinburgh, EH9 3JG, UK \\ ${ }^{3}$ Faculty of Veterinary Medicine, University of Thessaly, Trikalon 224, \\ 43100, Karditsa, Greece \\ ${ }^{4}$ Roslin Institute and Royal (Dick) School of Veterinary Studies Roslin BioCentre, \\ Midlothian EH25 9PS, UK
}

(Received 18 July 2007; accepted 21 December 2007)

\begin{abstract}
The wide range of genetic parameter estimates for production traits and nematode resistance in sheep obtained from field studies gives rise to much speculation. Using a mathematical model describing host - parasite interactions in a genetically heterogeneous lamb population, we investigated the consequence of: (i) genetic relationships between underlying growth and immunological traits on estimated genetic parameters for performance and nematode resistance, and (ii) alterations in resource allocation on these parameter estimates. Altering genetic correlations between underlying growth and immunological traits had large impacts on estimated genetic parameters for production and resistance traits. Extreme parameter values observed from field studies could only be reproduced by assuming genetic relationships between the underlying input traits. Altering preferences in the resource allocation had less pronounced effects on the genetic parameters for the same traits. Effects were stronger when allocation shifted towards growth, in which case worm burden and faecal egg counts increased and genetic correlations between these resistance traits and body weight became stronger. Our study has implications for the biological interpretation of field data, and for the prediction of selection response from breeding for nematode resistance. It demonstrates the profound impact that moderate levels of pleiotropy and linkage may have on observed genetic parameters, and hence on outcomes of selection for nematode resistance.
\end{abstract}

gastro-intestinal parasites / genetic parameters / modelling / disease resistance / sheep

\footnotetext{
*Corresponding author: Andrea.Wilson@sac.ac.uk 


\section{INTRODUCTION}

Gastro-intestinal parasitism constitutes a major challenge to the health, welfare and productivity of sheep worldwide. In the majority of cases sheep develop a sub-clinical disease, which may not be immediately apparent. The standard treatment to control the challenge has been the use of anthelminthics [30]. However, as with antibiotics, pathogen resistance to anthelminthics is an increasing problem [25]. Therefore, alternative strategies to control gastrointestinal parasitism are sought.

Increasing evidence for genetic variation in resistance to nematodes $[1,6,14]$ suggests selective breeding for resistance to nematodes as a valid tool for helping to control parasitism. Breeding for resistance requires knowledge of genetic parameters for host resistance and performance traits. Whilst heritabilities for faecal egg counts (FEC) and body weight are relatively consistent (e.g. 0.2-0.4), estimates of genetic correlations between FEC and body weight vary dramatically between studies, ranging from $-0.8[6]$ to $+0.4[17,18]$. These differences in the genetic parameter estimates have implications for the predicted direction and rate of genetic progress. In the case of the estimates of [6], lower FEC would be associated with higher body weight and therefore selection for reduced FEC would also lead to an increase in body weight. On the other hand, the estimates of $[17,18]$ imply that the two traits are positively associated and therefore selection to reduce FEC would be predicted to lead to lower body weight. Whilst there has been much speculation e.g. [5], the reasons for the discrepancies in the correlations remain unknown.

Parasite-host interactions are complex and difficult to elucidate. However, using in silico mathematical models these relationships can be explored in a way that captures the main characteristics of the host-parasite relationship. This has been illustrated by Vagenas et al. [28] who demonstrated timedependent changes in genetic parameters for nematode resistance and relationships with live weight. However, this model was based on various simplifying assumptions of the underlying biology. Several of these assumptions warrant further attention, as they are fundamental to the host control of parasitic infection. For example, all underlying traits (describing host control of parasite establishment, fecundity and mortality, as well as host lipid and protein deposition) were assumed to be uncorrelated. Despite the zero correlations in the underlying traits, output resistance and performance traits (e.g. faecal egg counts, worm burden, body weight, food intake) were correlated. However, correlations as extreme as those published from field data were not observed.

The assumption of zero correlation between the underlying traits is unlikely to hold, at least for the traits within a broad biological category (e.g. growth or 
resistance), since various processes may be controlled by similar genes or similar effector mechanisms [2]. Correlated underlying (input) traits, in line with biological expectations, could conceivably have a large impact on expected genetic parameter estimates for observable model output traits.

A second uncertainty refers to the nutrients, i.e. allocation of nutritional resources of infected animals. The allocation of nutrients towards maintenance, growth and immune processes is often thought to be one of the key driving forces that determines the relationship between production performance and resistance e.g. $[8,15,29]$, as it may lead to a trade-off between growth and immunity. A previous model assumed an allocation of available nutrients to immunity and performance traits in proportion to their requirements [26]. This assumption should be explored as it may impact on relationships between resistance and performance. Moreover, it is likely that long-term selection for either resistance or performance could alter the prioritisation towards growth or immunity, and hence result in populations with different resistance or performance characteristics as well as different relationships between resistance and performance.

This paper addresses the following questions: (i) how do genetic relationships between the underlying growth and resistance traits influence genetic parameter estimates for observed performance and parasitism? and (ii) how do preferences in the allocation of scarce nutrients towards growth or immunity affect the same set of genetic parameters?

\section{MATERIALS AND METHODS}

\subsection{The host-parasite interaction model}

The previously developed model of Vagenas et al. [28] describes the impact of host nutrition, genotype and gastro-intestinal parasitism on a population of growing lambs. The basic premise was that infestation of growing animals with gastro-intestinal parasites results in protein loss, modelled as a function of the worm population resident in the animal's gastro-intestinal tract. To counteract this loss of protein, animals invest in immune responses. Animals, which were assumed to be initially immunologically naïve, develop immunity as a function of their exposure to infective larvae. Three immunity traits were assumed to control the adult worm population: establishment (E) of incoming larvae, mortality (M) of adult worms and fecundity (F) of adult female worms.

The immune requirements for responding to infective larvae and adult worms are estimated separately and the total immune requirements were 
assumed to be the higher of the two, assuming thus common effector mechanisms for resistance to larvae and adult worms. The animals' nutrient intake is determined by the requirements for maintenance (including tissue repair), growth and immunity. For the in silico experiments carried out in this paper it was assumed that the food intake of a specific diet is ad libitum, but that infected animals may suffer anorexia, thus leading to reduced food intake [16]. In the allocation of resources, the maintenance needs of the animal were assumed to be satisfied first. In the original model of Vagenas et al. [26] it was assumed that any remaining protein is allocated to performance traits and immunity in proportion to their requirements. This assumption has been relaxed in this paper, and consequences of different allocation rules were investigated.

A schematic diagram describing the structure of the model is provided in Figure 1. The model equations and parameters relevant for this study are summarized in Appendix 1. A more detailed description of the model and its performance can be found in Vagenas et al. [26,27].

Between-animal variation was assumed in animal intrinsic growth abilities, in maintenance requirements, and in animal ability to resist or cope with gastro-intestinal parasites, as described by Vagenas et al. [28]. For growth processes, the underlying model parameters assumed to be under genetic control and thus varying between animals are the animal's initial empty body weight $\mathrm{EBW}_{0}$, protein and lipid mass at maturity, i.e. $\mathrm{P}_{\text {mat }}$ and $\mathrm{L}_{\text {mat }}$, respectively. The growth functions controlled by these parameters are shown in Appendix 1 (equations (1) and (2)). Variation in body maintenance was introduced via the coefficients $p_{\text {maint }}$ and $e_{\text {maint }}$, associated with protein and energy requirements for maintenance, respectively (equations (3) and (4) in Appendix 1). Genetic variation in the traits underlying the host's immune response is represented by the parameters $\mathrm{K}_{\mathrm{E}}, \mathrm{K}_{\mathrm{M}}$ and $\mathrm{K}_{\mathrm{F}}$ controlling the rates of larvae establishment (E), adult worm mortality (M) and fecundity (F), respectively (equations (5)-(7) in Appendix 1). Additionally, non-genetic variation is also introduced to the maxima of the traits $\left(\varepsilon_{\max }, \mu_{\max }, F_{\max }\right)$ and the minimum mortality rate $\mu_{\min }$ (same equations as above). The minima for fecundity and establishment were set to zero for all animals. Random environmental variation in daily food intake was assumed (SFI), to reflect the influence of external factors controlling food intake not accounted for explicitly by the model. All input parameters were assumed to be normally distributed. A list of the model parameters for which between-animal variation was assumed, together with the values of the corresponding genetic and phenotypic parameters, is provided in Table I. A sensitivity analysis to investigate the impact of changes in the parameter values on the model results has been carried out previously [28]. 


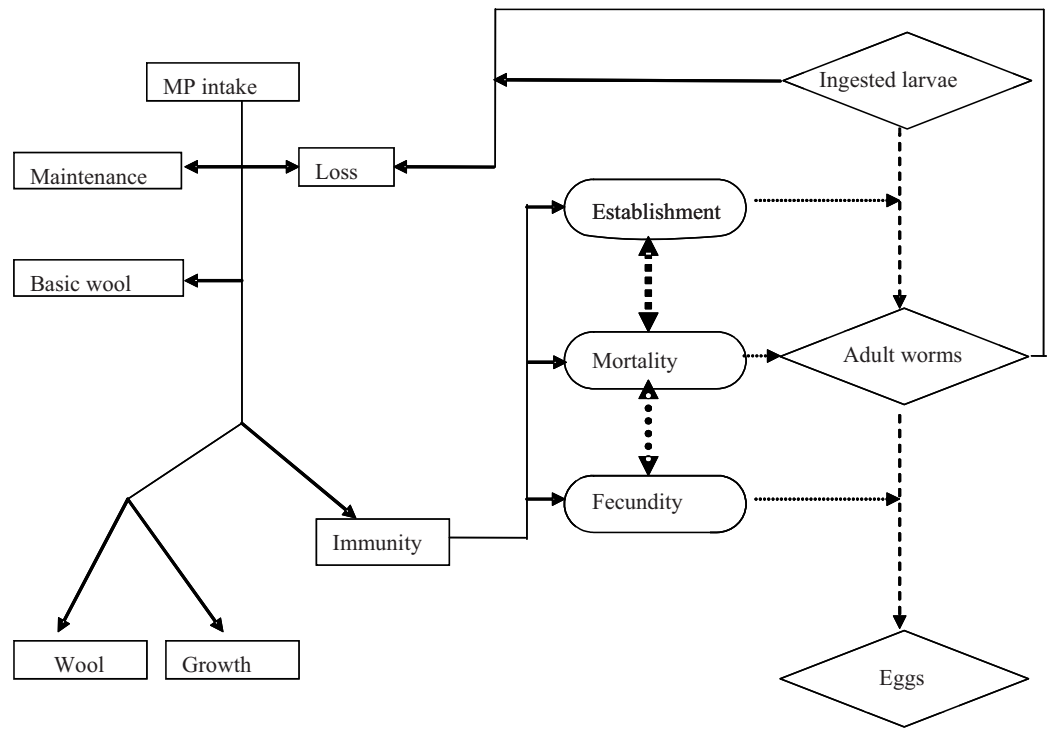

Figure 1. Schematic diagram of the host-parasite interaction model. Rectangular boxes indicate the fate of ingested protein, rounded boxes indicated host-parasite interactions and diamond boxes indicate key quantifiable parasite lifecycle stages. Dotted lines refer to the parasite lifecycle.

\subsection{Test assumption 1: Introducing co-variation between underlying input traits}

The underlying genetic input traits were assumed to be uncorrelated in previous simulation studies $[3,28]$. In this study, relationships between the underlying biological traits were created by introducing genetic covariances between the function parameters for which between-animal variation was assumed (Tab. I). Based on the lack of evidence to the contrary, a conservative assumption of zero environmental correlations between input traits was made; hence phenotypic correlations between input traits were weaker than genetic correlations.

As described by Vagenas et al. [28], animals were simulated within a predefined population structure, comprising founder animals, for which breeding values were simulated, and their progeny, for which phenotypes were created. Each founder animal has a breeding value $A$ for each genetically controlled input trait, sampled from a $N\left(0, \sigma_{\mathrm{A}}^{2}\right)$ distribution. The breeding value for each trait for each offspring is generated as $1 / 2\left(A_{\text {Sire }}+A_{\text {Dam }}\right)$ plus a Mendelian sampling term, drawn from a $N\left(0,0.5 \cdot \sigma_{\mathrm{A}}^{2}\right)$ distribution [13]. A Cholesky decomposition of the variance-covariance matrix for correlated traits is used 
Table I. Model parameters with assumed between-animal variation, and estimated values for the population mean, phenotypic coefficient of variation $\left(\mathrm{CV}=\right.$ mean $\left./ \sigma_{\mathrm{P}}\right)$ and heritability $\left(\mathrm{h}^{2}\right)$. Parameters that were assumed genetically correlated are marked in bold; see text for their correlations.

\begin{tabular}{|c|c|c|c|c|c|}
\hline $\begin{array}{c}\text { Model } \\
\text { parameter }\end{array}$ & Category & Description & Mean & $\mathbf{C V}^{*}$ & $\mathbf{h}^{2}$ \\
\hline $\mathbf{P}_{\text {mat }}$ & \multirow{3}{*}{ Growth } & Mature protein mass & 12.5 & 0.10 & 0.50 \\
\hline $\mathbf{L}_{\text {mat }}$ & & Mature lipid mass & 68.8 & 0.15 & 0.50 \\
\hline $\mathbf{E B W}_{\mathbf{0}}$ & & Initial body weight & 21.0 & 0.15 & 0.50 \\
\hline Pmaint & \multirow[t]{2}{*}{ Maintenance } & $\begin{array}{l}\text { Coefficient for } \\
\text { maintenance protein } \\
\text { requirements }\end{array}$ & 0.004 & 0.15 & 0.25 \\
\hline $\mathbf{e}_{\text {maint }}$ & & $\begin{array}{l}\text { Coefficient for } \\
\text { maintenance energy } \\
\text { requirements }\end{array}$ & 1.63 & 0.15 & 0.25 \\
\hline SFI & $\begin{array}{l}\text { Growth and } \\
\text { maintenance }\end{array}$ & $\begin{array}{l}\text { Deviation in daily food } \\
\text { intake }\end{array}$ & 0.00 & 0.05 & 0.00 \\
\hline$\varepsilon_{\max }$ & \multirow{7}{*}{ Resistance } & Max. establishment rate & 0.70 & 0.05 & 0.00 \\
\hline$\mu_{\max }$ & & Max. mortality rate & 0.11 & 0.05 & 0.00 \\
\hline$\mu_{\min }$ & & Min. mortality rate & 0.06 & 0.05 & 0.00 \\
\hline $\mathrm{F}_{\max }$ & & Max. fecundity rate & 20.0 & 0.05 & 0.00 \\
\hline $\mathbf{K}_{\mathbf{E}}$ & & $\begin{array}{l}\text { Rate parameter for larvae } \\
\text { establishment }\end{array}$ & $1 \times 10^{-5}$ & 0.25 & 0.25 \\
\hline $\mathbf{K}_{\mathbf{M}}$ & & $\begin{array}{l}\text { Rate parameter for worm } \\
\text { mortality }\end{array}$ & $1 \times 10^{7}$ & 0.50 & 0.25 \\
\hline$\overline{\mathbf{K}_{\mathbf{F}}}$ & & $\begin{array}{l}\text { Rate parameter for worm } \\
\text { fecundity }\end{array}$ & $1 \times 10^{7}$ & 0.70 & 0.25 \\
\hline
\end{tabular}

* Phenotypic variance $\left(\sigma_{\mathrm{P}}^{2}\right)=(\text { mean } \times \mathrm{CV})^{2}$.

to generate the covariances between the animals' breeding values. The phenotypic value, $\mathrm{Ph}_{i j}$, for each of the underlying traits is generated as:

$$
\mathrm{Ph}_{i}=\mu+\mathrm{A}_{i}+\mathrm{E}_{i}
$$

where: $\mu$ is the population mean for the trait, $\mathrm{A}_{i}$ is the additive genetic deviation of the $i^{\text {th }}$ individual, and $\mathrm{E}_{i}$ is the corresponding environmental deviation sampled from a normal distribution $N\left(0, \sigma_{\mathrm{P}}^{2}\left(1-\mathrm{h}^{2}\right)\right)$.

Appropriate values for the population means, the heritabilities and the phenotypic variations were derived in a previous study [28] and are shown in Table I. Only genetic correlations needed to be specified anew. Assuming non-zero genetic covariances between eight underlying biological traits results 
in 28 potential combinations of non-zero genetic correlations. This was reduced as follows: in stage 1, only correlations between traits within the same biological category, i.e. within growth, maintenance or resistance were considered, assuming zero correlations between traits in different categories. The latter assumption was dropped in stage 2, when correlations between categories of traits were varied, and correlations between traits within a category were fixed. In stage 1, non-zero correlations were either weak (0.25) or moderately strong (0.5). In stage 2, correlations between categories were set to moderately strong ( + or -0.5$)$, and correlations between traits within the same category were assumed to be weak (0.25), to ensure positive semi-definite covariance matrices.

Only relationships in line with our biological understanding were considered. Consequently, for maintenance traits, requirements for dietary energy and protein (equations (3) and (4) in Appendix 1) were always assumed to be positively related, as maintenance processes require both protein and energy [12]. Further, as body weight is generally positively correlated across time [20], it was assumed that the growth trait parameters $\mathrm{EBW}_{0}$ and $\mathrm{P}_{\mathrm{mat}}$, and $\mathrm{EBW}_{0}$ and $\mathrm{L}_{\text {mat }}$, respectively, are weakly positively correlated. For the maturity traits, $\mathrm{P}_{\text {mat }}$ and $\mathrm{L}_{\mathrm{mat}}$, both positive and negative genetic correlations were considered, representing breeds that evolved through different selection procedures (e.g. breeds selected for fast body weight growth $v s$. breeds selected for high lean and low fat content) or under different environmental conditions.

Manifold mechanisms, ranging from linkage and pleiotropic effects to common underlying effector mechanisms, could lead to both positive and negative relationships between the resistance traits. Thus, various combinations of correlations between the underlying resistance traits were considered. To ensure that the direction of relationships for the resistance traits was consistent, mortality was re-parameterised as survival $(\mathrm{S}=1-\mathrm{M})$. Thus higher values of $\mathrm{E}, \mathrm{S}$ and $\mathrm{F}$ all define a more susceptible animal.

Combinations of genetic correlations between traits belonging to the same category, that were investigated, are summarized in Table II. Likewise, Table III shows the combinations of genetic correlations between traits of different categories. Explored scenarios included both positive and negative correlations between underlying growth, maintenance and resistance traits, representing situations in which: (i) animals with a higher genotype for growth are simultaneously more resistant to gastro-intestinal parasites, and (ii) situations in which growth and resistance are competing processes, respectively. 
Table II. Simulated scenarios and the associated genetic correlations between traits within the same category (growth, maintenance, resistance).

\begin{tabular}{|c|c|c|c|c|}
\hline $\begin{array}{l}\text { Simulated } \\
\text { scenario }\end{array}$ & $\begin{array}{l}\text { Underlying } \\
\text { biol. traits } \\
\text { (UBTs) }\end{array}$ & $\begin{array}{c}\text { Genetic } \\
\text { relationship } \\
\text { between } \\
\text { UBTs }\end{array}$ & $\begin{array}{c}\text { Genetic correlation } \\
\text { between model } \\
\text { parameters }\end{array}$ & Underlying assumption \\
\hline & & & Growth traits & \\
\hline $\begin{array}{l}\text { Gpos \& } \\
\text { Gneg }\end{array}$ & $\mathrm{EBW}_{0}, \mathrm{P}_{\mathrm{mat}}$ & $\begin{array}{l}\text { Weakly } \\
\text { positive }\end{array}$ & $\begin{array}{l}\mathrm{r}_{\mathrm{g}}\left(\mathrm{EBW}_{0}, \mathrm{P}_{\mathrm{mat}}\right)= \\
0.25\end{array}$ & \multirow{2}{*}{$\begin{array}{l}\text { Weaning and mature weight } \\
\text { - positively genetically } \\
\text { correlated }\end{array}$} \\
\hline $\begin{array}{l}\text { Gpos \& } \\
\text { Gneg }\end{array}$ & $\mathrm{EBW}_{0}, \mathrm{~L}_{\text {mat }}$ & $\begin{array}{l}\text { Weakly } \\
\text { positive }\end{array}$ & $\begin{array}{l}\mathrm{r}_{\mathrm{g}}\left(\mathrm{EBW}_{0}, \mathrm{~L}_{\text {mat }}\right)= \\
0.25\end{array}$ & \\
\hline Gpos & $\mathrm{P}_{\mathrm{mat}}, \mathrm{L}_{\mathrm{mat}}$ & $\begin{array}{l}\text { Moderately } \\
\text { positive }\end{array}$ & $\begin{array}{l}\mathrm{r}_{\mathrm{g}}\left(\mathrm{P}_{\mathrm{mat}}, \mathrm{L}_{\mathrm{mat}}\right)= \\
0.5\end{array}$ & $\begin{array}{l}\text { Corresponding to breeds in } \\
\text { which lean and fat content are } \\
\text { positively related }\end{array}$ \\
\hline Gneg & $\mathrm{P}_{\text {mat }}, \mathrm{L}_{\mathrm{mat}}$ & $\begin{array}{l}\text { Moderately } \\
\text { positive }\end{array}$ & $\begin{array}{l}\mathrm{r}_{\mathrm{g}}\left(\mathrm{P}_{\mathrm{mat}}, \mathrm{L}_{\mathrm{mat}}\right)= \\
-0.5\end{array}$ & $\begin{array}{l}\text { Corresponding to breeds in } \\
\text { which lean and fat content are } \\
\text { negatively related }\end{array}$ \\
\hline \multicolumn{5}{|c|}{ Maintenance traits } \\
\hline Mpos & $\mathrm{p}_{\text {maint }}, \mathrm{e}_{\text {maint }}$ & $\begin{array}{l}\text { Moderately } \\
\text { positive }\end{array}$ & $\begin{array}{l}\mathrm{r}_{\mathrm{g}}\left(\mathrm{p}_{\text {maint }}, \mathrm{e}_{\text {maint }}\right)= \\
0.5\end{array}$ & $\begin{array}{l}\text { Genetic variation applies to } \\
\text { both protein and energy } \\
\text { demands for maintenance } \\
\text { processes }\end{array}$ \\
\hline \multicolumn{5}{|c|}{ Susceptibility traits } \\
\hline \multirow{3}{*}{ Rpos } & E, S & $\begin{array}{l}\text { Moderately } \\
\text { positive }\end{array}$ & $\begin{array}{l}\mathrm{r}_{\mathrm{g}}\left(\mathrm{K}_{\mathrm{E}}, \mathrm{K}_{\mathrm{M}}\right)= \\
-0.5\end{array}$ & \multirow{3}{*}{$\begin{array}{l}\text { Linkage, pleiotropy or common } \\
\text { effector mechanisms operate on all } \\
\text { underlying resistance traits in the } \\
\text { same direction. Resistant } \\
\text { genotypes refer to resistance in all } \\
\text { three traits S, E and F. }\end{array}$} \\
\hline & $\mathrm{E}, \mathrm{F}$ & $\begin{array}{l}\text { Moderately } \\
\text { positive }\end{array}$ & $\begin{array}{l}\mathrm{r}_{\mathrm{g}}\left(\mathrm{K}_{\mathrm{E}}, \mathrm{K}_{\mathrm{F}}\right)= \\
-0.5\end{array}$ & \\
\hline & S, F & $\begin{array}{l}\text { Moderately } \\
\text { positive }\end{array}$ & $\begin{array}{l}\mathrm{r}_{\mathrm{g}}\left(\mathrm{K}_{\mathrm{M}}, \mathrm{K}_{\mathrm{F}}\right)= \\
0.5\end{array}$ & \\
\hline \multirow{3}{*}{ Rneg } & E, S & $\begin{array}{l}\text { Moderately } \\
\text { negative }\end{array}$ & $\begin{array}{l}\mathrm{r}_{\mathrm{g}}\left(\mathrm{K}_{\mathrm{E}}, \mathrm{K}_{\mathrm{M}}\right)= \\
0.5\end{array}$ & \multirow{3}{*}{$\begin{array}{l}\text { Linkage, pleiotropy or common } \\
\text { effector mechanisms operate on } \\
\text { the underlying resistance traits in } \\
\text { opposite directions. Genotypes } \\
\text { that are resistant with respect to } \\
\text { one trait are thus susceptible with } \\
\text { respect to another trait. }\end{array}$} \\
\hline & E, F & $\begin{array}{l}\text { Moderately } \\
\text { negative }\end{array}$ & $\begin{array}{l}\mathrm{r}_{\mathrm{g}}\left(\mathrm{K}_{\mathrm{E}}, \mathrm{K}_{\mathrm{F}}\right)= \\
0.5\end{array}$ & \\
\hline & S, F & $\begin{array}{l}\text { Moderately } \\
\text { negative }\end{array}$ & $\begin{array}{l}\mathrm{r}_{\mathrm{g}}\left(\mathrm{K}_{\mathrm{M}}, \mathrm{K}_{\mathrm{F}}\right)= \\
-0.4^{\dagger}\end{array}$ & \\
\hline
\end{tabular}

$\dagger$ The value -0.5 led to a non positive semi-definite variance-covariance matrix.

\subsection{Test assumption 2: Changing preferences in the allocation of dietary protein}

The model of Vagenas et al. [26] builds upon protein as the driving resource for growth and immune response. Available dietary protein was originally allocated to growth $\left(\mathrm{P}_{\mathrm{G}}\right)$ and immunity $\left(\mathrm{P}_{\mathrm{I}}\right)$ in proportion to the requirements of these processes [26]. In this study, priority towards growth or immunity has 
Table III. Simulations and the associated relationships between traits of different categories (growth, maintenance, resistance), for which results are presented. The genetic correlations between all parameters associated with different categories considered were set to either 0.5 or -0.5 for moderately positive or negative genetic relationships, respectively. Weakly positive genetic correlations were assumed between the traits in the same category.

\begin{tabular}{|c|c|c|c|c|}
\hline Simulation & Categories & $\begin{array}{l}\text { Underlying } \\
\text { biol. traits } \\
\text { (UBTs) }\end{array}$ & $\begin{array}{c}\text { Genetic } \\
\text { relationship } \\
\text { between UBTs }\end{array}$ & $\begin{array}{c}\text { Underlying } \\
\text { assumptions }\end{array}$ \\
\hline GRpos & \multirow{2}{*}{$\begin{array}{l}\text { Growth and } \\
\text { resistance }\end{array}$} & \multirow{2}{*}{$\begin{array}{c}\mathrm{EBW}_{0} \\
\mathrm{P}_{\text {mat }}, \mathrm{L}_{\text {mat }} \\
\text { and } \\
\mathrm{E}, \mathrm{S}, \mathrm{F}^{*}\end{array}$} & $\begin{array}{l}\text { Moderately } \\
\text { negative }\end{array}$ & $\begin{array}{l}\text { Fast growing genotypes } \\
\text { with high mature weight } \\
\text { tend to be less susceptible } \\
\text { (more resistant) to parasites }\end{array}$ \\
\hline GRneg & & & $\begin{array}{l}\text { Moderately } \\
\text { positive }\end{array}$ & $\begin{array}{l}\text { Fast growing genotypes } \\
\text { with high mature weight } \\
\text { tend to be more susceptible } \\
\text { (less resistant) to parasites }\end{array}$ \\
\hline GMpos & \multirow{2}{*}{$\begin{array}{l}\text { Growth and } \\
\text { maintenance }\end{array}$} & \multirow{2}{*}{$\begin{array}{l}\mathrm{EBW}_{0}, \mathrm{P}_{\text {mat }}, \\
\mathrm{L}_{\text {mat }} \\
\text { and } \\
\mathrm{p}_{\text {maint }}, \mathrm{e}_{\text {maint }}\end{array}$} & $\begin{array}{l}\text { Moderately } \\
\text { positive }\end{array}$ & $\begin{array}{l}\text { Fast growing genotypes } \\
\text { with high mature weight } \\
\text { tend to have high resource } \\
\text { requirements for } \\
\text { maintenance processes }\end{array}$ \\
\hline GMneg & & & $\begin{array}{l}\text { Moderately } \\
\text { negative }\end{array}$ & $\begin{array}{l}\text { Fast growing genotypes } \\
\text { with high mature weight } \\
\text { tend to have low resource } \\
\text { requirements for } \\
\text { maintenance processes }\end{array}$ \\
\hline RMpos & \multirow{2}{*}{$\begin{array}{l}\text { Resistance } \\
\text { and } \\
\text { maintenance }\end{array}$} & \multirow{2}{*}{$\begin{array}{l}\mathrm{E}, \mathrm{S}, \mathrm{F} \\
\text { and } \\
\mathrm{p}_{\text {maint }}, \mathrm{e}_{\text {maint }}\end{array}$} & $\begin{array}{l}\text { Moderately } \\
\text { negative }\end{array}$ & $\begin{array}{l}\text { Susceptible genotypes tend } \\
\text { to have low resource } \\
\text { requirements for } \\
\text { maintenance processes }\end{array}$ \\
\hline RMneg & & & $\begin{array}{l}\text { Moderately } \\
\text { positive }\end{array}$ & $\begin{array}{l}\text { Susceptible genotypes tend } \\
\text { to have high resource } \\
\text { requirements for } \\
\text { maintenance processes }\end{array}$ \\
\hline
\end{tabular}

* E, S and $\mathrm{F}$ define animal susceptibility; high values imply high susceptibility.

been introduced by using a constant $s$ that assumes real values between 0 and 2 , with the current allocation rule corresponding to $s=1$.

Let $\mathrm{P} *_{\mathrm{G}}$ and $\mathrm{P} *_{\mathrm{I}}$ be the required dietary protein for growth and immunity, respectively. Then, if $0 \leqslant s<1$, growth is prioritised over immunity, and the proportions of available dietary protein allocated to immunity and growth are:

$$
\mathrm{P}_{\mathrm{I}}=s \frac{\mathrm{P}^{*}{ }_{\mathrm{I}}}{\mathrm{P}^{*}{ }_{\mathrm{I}}+\mathrm{P}_{\mathrm{G}}^{*}}
$$


and

$$
\mathrm{P}_{\mathrm{G}}=\frac{\mathrm{P}^{*}{ }_{\mathrm{G}}+(1-s) \mathrm{P}_{\mathrm{I}}^{*}}{\mathrm{P}^{*}{ }_{\mathrm{I}}+\mathrm{P}^{*}{ }_{\mathrm{G}}}
$$

If, $1<s \leqslant 2$, immunity is prioritised over growth, and the proportions of dietary protein allocated to growth and immunity are:

$$
\mathrm{P}_{\mathrm{G}}=(2-s) \frac{\mathrm{P}^{*}{ }_{\mathrm{G}}}{\mathrm{P}^{*}{ }_{\mathrm{I}}+\mathrm{P}_{\mathrm{G}}^{*}}
$$

and

$$
\mathrm{P}_{\mathrm{I}}=\frac{\mathrm{P}_{\mathrm{I}}^{*}+(s-1) \mathrm{P}^{*}{ }_{\mathrm{G}}}{\mathrm{P}^{*}{ }_{\mathrm{I}}+\mathrm{P}_{\mathrm{G}}^{*}} .
$$

It is possible from equations ( $1 \mathrm{a}$ and $1 \mathrm{~b})$ and $(2 \mathrm{a}$ and $2 \mathrm{~b})$ that the dietary protein allocated to the process of higher priority (i.e. growth or immunity) exceeds the animals' requirements. If this is the case, the excess dietary protein is reallocated to the process of lower priority.

\subsection{Simulation procedure}

The simulated flock comprised 10000 lambs, which were assumed to be twins from a non-inbred, unrelated base population of 250 rams each mated with 20 randomly chosen ewes. Input phenotypes were simulated as described above. Animals were assumed to be initially naïve and infected with a trickle challenge of 3000 L3 Teladorsagia circumcincta, which corresponded to subclinical infection [9]. Animals were assumed to have ad-libitum access to relatively poor quality grass $\left(7.5 \mathrm{MJ} \cdot \mathrm{kg}^{-1} \mathrm{DM} \mathrm{ME}\right.$ and $\left.0.097 \mathrm{~kg} \mathrm{CP} \cdot \mathrm{kg}^{-1} \mathrm{DM}\right)$, which implied that the nutrient requirements for both growth and immunity could not always be satisfied [27,28].

The model predicts growth performance and immune response for each individual on a daily basis for a time period of four months from weaning. Results are mainly presented for the predicted food intake, daily gain in body protein and empty body weight as observable production traits, and for faecal egg counts and worm burden as indicator resistance traits. A natural log transformation was applied to the latter two traits to render them close to normality. Whereas the genetic parameters of the underlying traits were assumed to be known, genetic parameters of the observable production and resistance output traits had to be estimated. Population means were estimated daily, whereas heritabilities and correlations were estimated for time points up to ten days apart. Genetic variances and co-variances of the model output traits, and hence heritabilities and genetic/phenotypic correlations, were estimated from a linear 
mixed model, fitting sire as a random effect. The presented results refer to one simulated flock of 10000 lambs.

\section{RESULTS}

\subsection{Test assumption 1: Underlying biological traits are genetically related}

The phenotypic means and variances of the output traits were not substantially affected by the introduction of genetic correlations between the underlying traits. Additionally, in all simulations the phenotypic correlations, although generally weaker than the genetic correlations, showed trends that were similar to the corresponding genetic correlations. Thus, only results for genetic correlations are presented. Furthermore, the effects of altering correlations involving maintenance traits were generally weak or negligible, compared to the effects generated by correlating growth and resistance traits. Therefore, the results focus on the impact of correlated input growth and resistance traits.

\subsubsection{Effects of correlations between underlying traits of the same category}

Variation in the correlations between the underlying growth traits $\mathrm{EBW}_{0}$, $\mathrm{P}_{\text {mat }}$ and $\mathrm{L}_{\mathrm{mat}}$, had minor effects on the heritability estimates of production traits (e.g. protein retention PR, lipid retention LR, food intake FI, empty body weight EBW). These were only apparent as the animals matured (> 80 days post infection). It had negligible impact on the heritabilities of the output resistance traits (transformed WB and FEC). Likewise, introducing correlations between underlying resistance traits primarily affected the heritabilities of the output resistance traits. Assuming positive correlations between input resistance traits substantially increased the heritabilities of WB and FEC, bringing the FEC heritability more in line with published values (i.e. $\mathrm{h}^{2}$ ca. 0.3 from 30 days post infection). Conversely, negative input correlations reduced these heritabilities, and they stabilised close to 0.1 .

Varying the genetic correlations between the input growth traits mainly affected the correlations between body protein and lipid retention, but again only after 80 days post infection. Impacts were negligible on the estimated correlation between FI and EBW and on output resistance traits.

Varying the genetic relationships between the underlying resistance traits did not impact on performance traits, but it had a strong impact on the genetic 

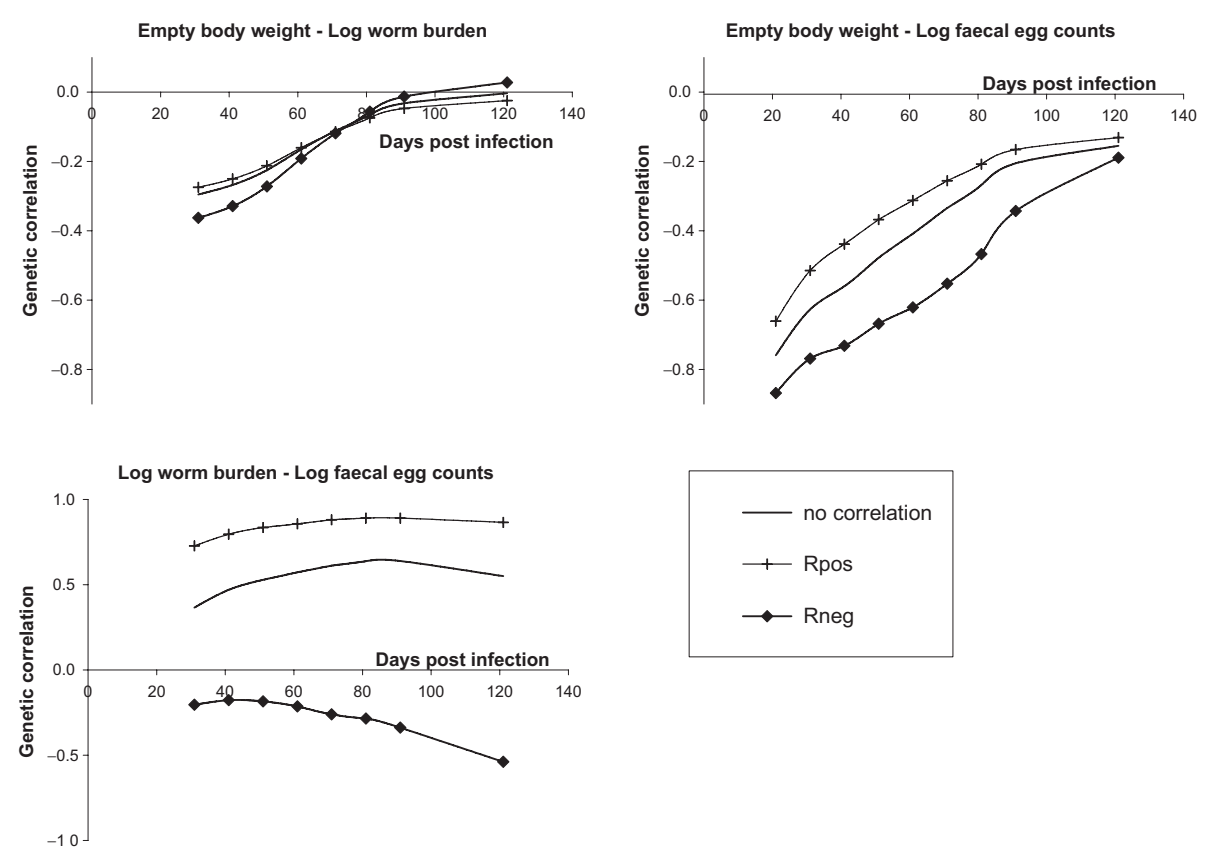

Figure 2. Impact of correlations between underlying resistance traits on estimated genetic and phenotypic correlations between observable production and resistance traits. Notations are as described in Table II. The average estimated standard errors for the correlations were 0.07 (EBW and $\ln (\mathrm{WB})$ ), 0.06 (EBW and $\ln (\mathrm{FEC})$ ) and 0.08 $(\ln (\mathrm{WB})$ and $\ln (\mathrm{FEC}))$.

correlations between the output resistance traits (Fig. 2). Positive input correlations made the genetic correlation between WB and FEC more positive, increasing from ca. 0.5 to ca. 0.9 , whereas negative input correlations made this relationship marginally negative. Genetic correlations between underlying resistance traits also influenced the correlations between output resistance and performance traits, although these were always negative and declined towards zero with age and immunity acquisition. Negative correlations between input resistance traits led to a slightly stronger correlation between EBW and FEC (Fig. 2).

\subsubsection{Effects of correlations between underlying traits of different categories}

Positive genetic correlations between input performance and resistance traits generally increased the heritabilities of output traits, whereas the converse was seen for negative correlations between trait categories. The effect was larger 

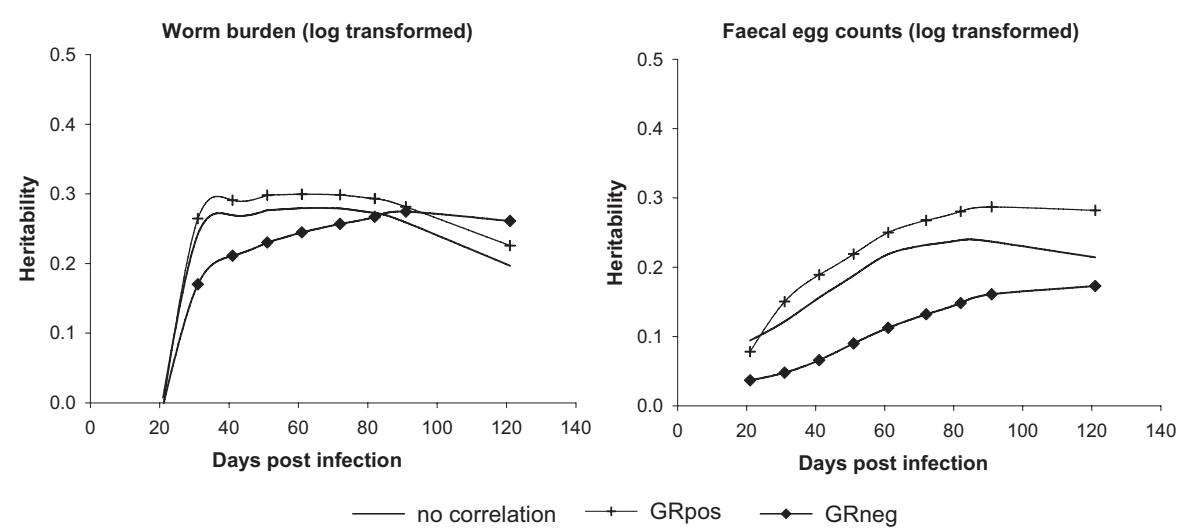

Figure 3. Effect of correlation between underlying resistance and growth traits on the estimated heritabilities of transformed WB and FEC. Notations are as described in Table III. Environmental correlations were assumed to be zero. The estimated standard errors were on average 0.02 for both $\ln (\mathrm{WB})$ and $\ln (\mathrm{FEC})$.

for resistance traits. Heritabilities of output resistance traits are illustrated in Figure 3. The impact of the input trait correlations was larger for FEC (a combination of larvae establishment, worm mortality and faecal output) than for WB. Furthermore, these input correlations affect the heritability time trends of FEC and WB differently. For WB, changes in heritabilities were directly associated with changes in absolute WB. Negative correlations between growth and resistance input traits resulted in a FEC heritability that was generally lower than published values.

Correlations between resistance and performance input traits generally did not affect correlations between output traits within categories, the exception being the correlation of WB and FEC, as illustrated in Figure 4. In this case, a negative relationship between the input growth and resistance traits (GRneg in Tab. III) resulted in negative genetic correlations between (transformed) WB and FEC in early stages of infection when variation in worm burden is low and variation in FEC, in the model, is primarily controlled by variation in food intake. This effect largely disappeared 30 days post first infection.

It was only by incorporating correlations between underlying resistance and performance traits that the simulation model was able to reproduce genetic correlations (ca. -0.8) similar to extreme published values (Fig. 4). For example, favourable correlations between input resistance and performance traits (GRpos in Tab. III) resulted in strong negative correlations between empty body weight and FEC or WB, and these correlations were stable across time. Conversely, unfavourable input correlations (i.e. GRneg, better expected 

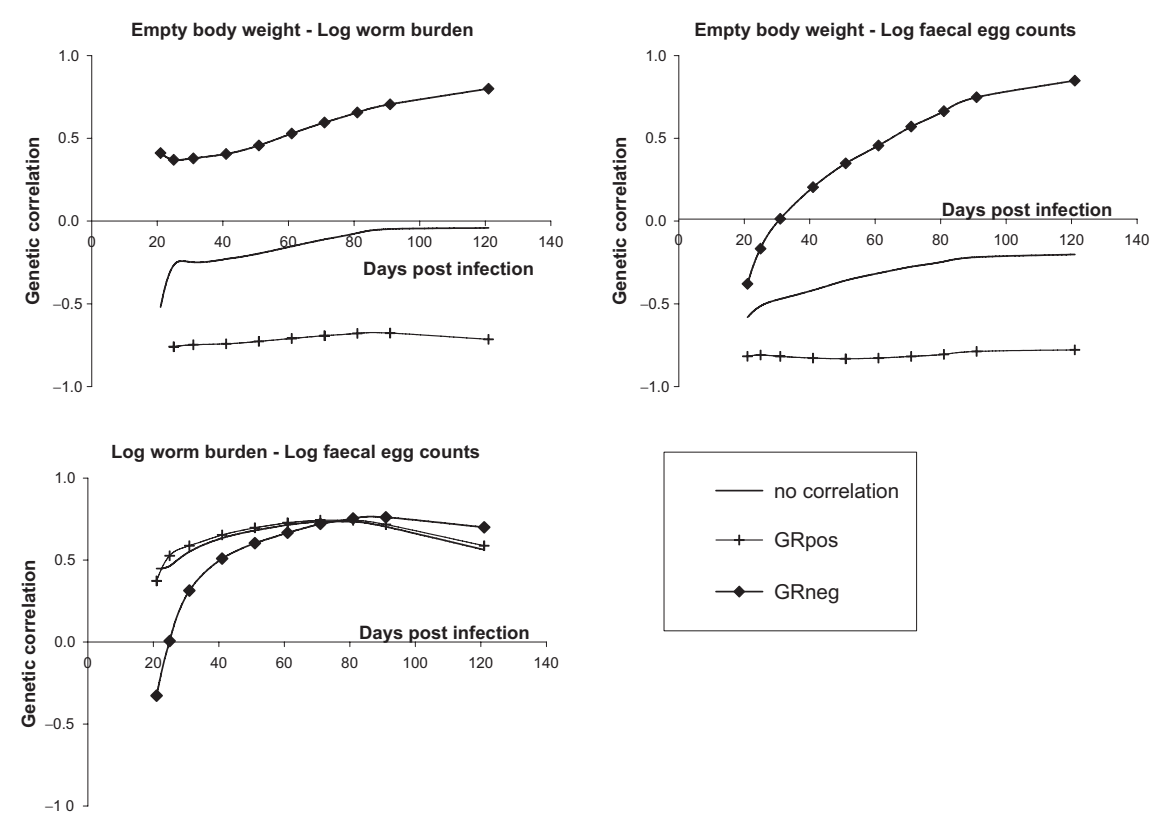

Figure 4. Impact of correlations between underlying resistance and growth traits on estimated genetic correlations between observable production and resistance traits. Notations are as described in Table III. The average estimated standard errors for the correlations were $0.06(\mathrm{EBW}$ and $\ln (\mathrm{WB})), 0.08$ (EBW and $\ln (\mathrm{FEC}))$ and 0.08 $(\ln (\mathrm{WB})$ and $\ln (\mathrm{FEC}))$.

growth attributes are associated with poorer resistance, and vice versa) produced antagonistic correlations between EBW and FEC or WB. Moreover, in this case, the correlation with FEC varied considerably over time, being weak and favourable in the early stages of infection, and then becoming progressively more antagonistic.

\subsection{Test assumption 2: Preference in resource allocation towards growth or immunity}

Different prioritisations of available nutrients (dietary protein) towards growth or immunity had little impact on the performance trait means, but it did affect the resistance trait means. As shown in Figure 5a, animals that give full priority to growth over immunity ( $s=0$ in equations (1a), (1b)) had an average peak WB twice as high as animals that allocated available dietary protein according to the requirements of growth and immunity. Also, in these cases, the maxima for both average WB and FEC occurred approximately 10 days later. 
The impact of prioritisation on average WB and FEC decreased during the later stages of infection as immunity was acquired (Figs. 5a and 5b). In contrast, full prioritisation of immunity over growth had smaller impacts on average WB and FEC (Figs. 5a and 5b).

Changing priorities in nutrient allocation had negligible effects on phenotypic variances and heritabilities of the output production traits or on phenotypic variances of the resistance traits. However, nutrient allocation priority had transient effects on the heritabilities of FEC and WB. For WB, higher heritabilities corresponded with higher mean WB when nutrients were preferentially allocated to performance traits (Fig. 5c). For the same scenario, heritabilities for FEC increased to a plateau quicker than for the other allocation scenarios (Fig. 5d).

The largest impact of altering the allocation of dietary protein was observed on the genetic correlations between the output resistance traits. Transformed WB and FEC were positively correlated for all values of the allocation coefficient $s$. However, correlations increased with decreasing $s$ (shifting priority towards growth) during the phase of acquisition of immunity (up to 80 days post first infection). Preferences in nutrient allocation had an even stronger impact on the genetic correlations between performance and resistance traits. For example, when immunity was fully prioritised over growth ( $s=2$ in equations (2a), (2b)), there was no association between EBW and transformed WB. In contrast, when full priority was given to growth $(s=0$ in equations (1a), (1b)), strong negative genetic correlations between EBW and transformed WB were obtained (Fig. 5e). These results suggest that if challenged animals initially allocate a proportion of dietary protein towards growth as opposed to immunity, WB increases and eventually a trade-off between growth and WB occurs, with the trade-off increasing as the prioritisation of protein towards growth increases. A similar, albeit weaker, trend was observed for the genetic correlations between EBW and transformed FEC (Fig. 5f). The trend was weaker since the correlations are partly influenced by the dependence of FEC on volume of faeces produced, which is indirectly related to EBW.

\section{DISCUSSION}

We have investigated the consequences of various assumptions made when modelling host-parasite interactions in populations of sheep infected with nematode parasites. It has been demonstrated that in many, but not all, instances the model predictions depend greatly on the assumed genetic architecture of the input traits. Generally the observed effects are greater for resistance than 
(a) Worm burden (WB)

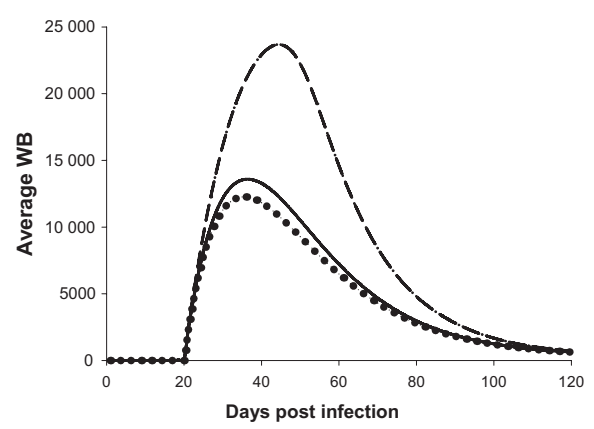

(c) Worm burden (WB)

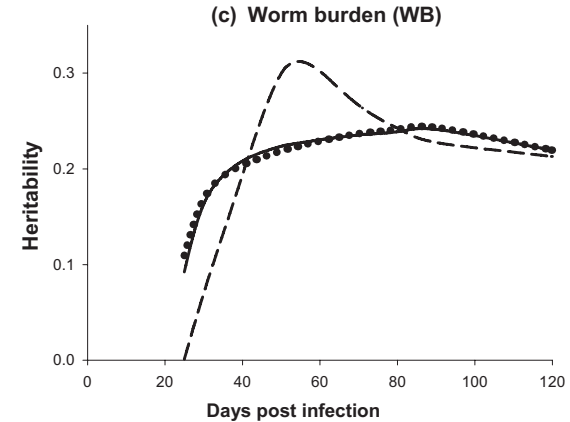

(e) EBW - WB (log)

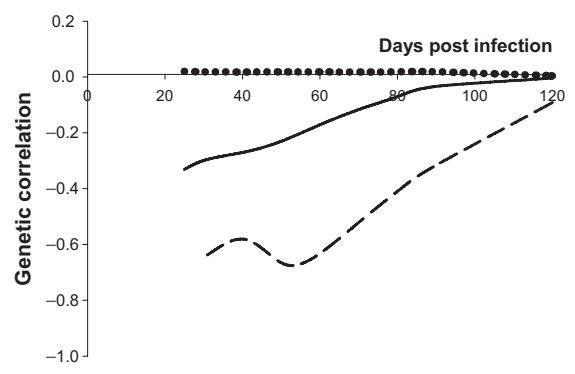

(b) Faecal egg counts (FEC)

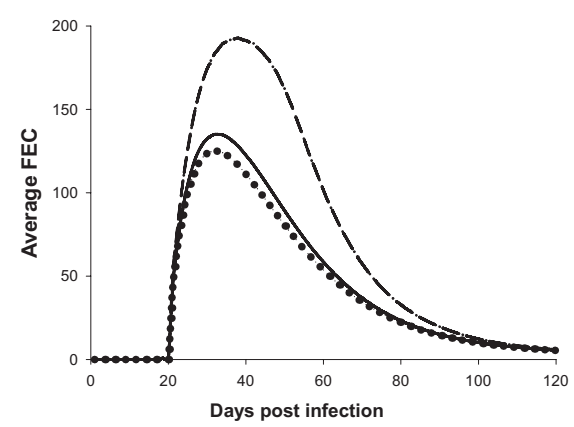

(d) Faecal egg counts (FEC)

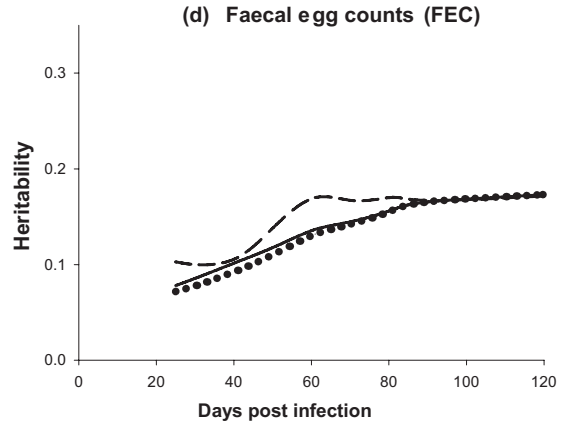

(f) EBW - FEC (log)

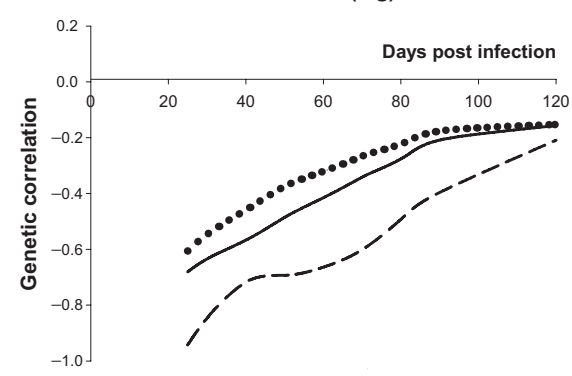

$s=1 \quad---s=0 \quad \cdots \cdots \cdot s=2$

Figure 5. Effects of preferences in the nutrient allocation on trait means, heritabilities and genetic correlations. $s=1$ refers to allocation according to requirements, $s=0$ refers to full priority towards growth (equations (1a), (1b)), and $s=2$ refers to full priority towards immunity (equations $(2 \mathrm{a}),(2 \mathrm{~b}))$. 
for growth traits, and it is the genetic correlations between output traits that are most sensitive to input assumptions. Further, the effects are of sufficient magnitude that the interpretation of the model may change according to the input assumptions, e.g. observed correlations between FEC and EBW can change from negative to positive. Altering the prioritisation of nutrients towards growth or immunity, as modelled in this paper, has effects that are less dramatic, affecting mainly the genetic correlations between resistance and performance, while having smaller effects on trait means, heritabilities or variability. By definition, this impact will depend on the degree of protein scarcity, and the quantity of dietary protein required to mount an appropriate immune response.

Genetic correlations between performance and indicator resistance traits are of particular importance in practical situations. Numerous field studies have revealed these correlations to be non-zero for growing lambs $[6,7,17,18]$ and non-zero correlations have also been found in previous modelling studies e.g. $[4,5,28]$. However, it is notable that these modelling studies failed to produce values as extreme as those reported by Bishop et al. [6] (-0.8) or McEwan et al. $[17,18](+0.4)$. In this study, correlations of these magnitudes between body weight and FEC were produced simply by assuming that underlying growth and resistance traits were correlated. Furthermore, the strong output correlations observed in Figure 4 suggest that the correlations between underlying traits need not be strong to achieve such an effect. Chance effects and population stratification may be sufficient to induce a non-zero genetic correlation between underlying traits that govern competing processes such as growth and immunity, and hence lead to strong correlations among the observed traits.

Detailed studies of the host immune response to gastro-intestinal parasites in small ruminants $[2,19]$ demonstrate that host resistance comprises a cascade of immune mechanisms adapted to different parasite life-cycle stages. It is also proposed that different types of immune responses may be counter-regulatory [14]. Our relatively simple model distinguishes between three host-controlled processes, i.e. larvae establishment, worm survival and adult worm fecundity. Knowing the relationship between these underlying processes is vital for the establishment of successful selection programmes. If, for example, underlying immunological traits are negatively correlated, so that genetic improvement in one immune trait triggers simultaneous deterioration of another trait involved in different aspects of the immune response, a refinement of the term 'resistance' and its implementation into breeding programs may be necessary. The genetic correlations between WB and FEC produced by the model illustrates this issue, since negative genetic correlations between these 
output resistance traits would imply a conflict between two desired breeding goals, i.e. low worm burden and low pasture contamination.

The WB $v s$. FEC relationship also illustrates that exploration of the model properties can lead to insights into expected underlying relationships. Whilst published parameter estimates are scarce, available estimates are positive and strong [11]. Thus, the results presented in Figure 2 suggest that the correlations between input establishment, fecundity and mortality traits are probably at least neutrally and more likely positively associated. Therefore, it is likely that similar genes or effector mechanisms influence them. This conclusion is reinforced by heritabilities observed for FEC: only when the underlying genetic correlations were positive the heritabilities were close to the values of 0.2 to 0.4 generally seen in literature [14].

Time trends in the output trait heritabilities and correlations (Figs. 2-4) are also of interest, and mirror effects previously seen in field data [10]. The strongest effect was observed for genetic correlations between EBW and FEC, which differed markedly between scenarios where growth was positively and negatively associated with resistance, respectively (Fig. 4). In the case of a positive genetic association, genetic correlations between EBW and FEC were negative and almost constant over time. In contrast, a negative genetic association led to a strong increase from initially negative to eventually strongly positive correlations between EBW and transformed FEC. In this case, the moderately strong initial negative genetic correlation between EBW and FEC probably stems from the fact that WB is low and variation in FEC, at least in this model, is primarily controlled by variations in volume of faeces produced. The gradual increase towards strongly positive correlations reflects the cumulative impact of the host response on performance and resistance traits. It should also be noted that in this study a trickle challenge of larvae was assumed. In reality, the infectious challenge a sheep faces is likely to vary with pasture intake and hence the degree of anorexia the animal has been undergoing.

The second issue explored in this study was the allocation of resources by immunologically challenged animals. Resource allocation has been postulated as a driving factor for correlations between traits [15,24]. The theory predicts that negative correlations arise when various processes have to compete for resources, whereas positive correlations between traits arise if both traits share resource for their development and resource availability increases. Several researchers have adapted the resource allocation theory to the animal breeding context to demonstrate, theoretically, that artificial selection can influence how animals allocate available resources and the impact this may have on the 
genetic correlations between traits [21-23, 29]. However, resource allocation theory tends to concentrate on the total rather than the net cost of competing processes, e.g. it ignores the benefits of mounting an immune response. By definition, the impacts of alterations in resource allocation depend on the degree to which resources are scarce and the relative requirements of the two competing processes. If resources are not scarce, or if the resource required for the competing process is small, then large impacts of altering resource allocation cannot be expected.

We found that preferences in the resource allocation towards growth or immunity had an impact on some of the estimated genetic parameters of the resistance traits and their relationship to production traits. However, the observed impact was weaker than that produced by altering genetic correlations between underlying biological traits. Moreover, the effects were non-symmetric between prioritising towards growth $v s$. immunity, with major effects occurring only when full prioritisation was towards growth. This indicates that a large proportion of immune requirements could be met by the original allocation rule. The asymmetry is also attributable to the model assumptions that nutrient requirements for immunity are considerably smaller than those for growth (the maximum requirements of dietary protein for immunity and damage repair were assumed to be $20 \%$ and $6 \%$ of the maintenance protein requirements, respectively, 26). As a consequence, a shift in priority towards immunity would lead to a relatively small loss of resources for growth. This leaves anorexia as a potentially significant factor for reducing growth rate. However, for the diet used in this model, bulkiness of the food was more limiting than loss in appetite. Mean voluntary feed intake was therefore similar between animals that differed only in their nutrient allocation preference.

Finally, the simulations in this study explored extreme cases of resource allocation, assuming that all animals in a population have the same preference for nutrient allocation. In reality, individual animals may differ in their preference, and the preference may be heritable. In this case, resource allocation and relationships between different categories of traits may become related phenomena. It is plausible that genetic variation in this preference may well affect genetic parameters for production and indicator resistance traits, and this would be an interesting area for future investigation.

\section{CONCLUSIONS}

In this study, likely impacts of various biological uncertainties influencing host-parasite interactions on expected genetic parameters for performance and 
indicator resistance traits in sheep infected with gastro-intestinal parasites were examined. Altering genetic relationships between underlying input traits and preferences in the allocation of available dietary protein to growth or immunity both had significant effects on the genetic parameters of relevant traits. However, the impacts of varying relationships between input traits were generally larger than altering resource allocation, for the scenarios modelled. In fact, extreme parameters values observed from field data could only be created by assuming genetic relationships between input traits. These results suggest that a better knowledge of the relationship between underlying biological processes for growth performance (e.g. protein and lipid accretion) and for resistance (e.g. worm establishment, survival and fecundity) is required for an accurate prediction of the genetic properties of resistance to gastro-intestinal parasites. This would have implications on the practical feasibility of selecting for resistance to parasites as a means of parasite control in the absence of input from anthelmintics.

\section{ACKNOWLEDGEMENTS}

We wish to thank the Biotechnology and Biological Sciences Research Council and the Scottish Executive Environment and Rural Affairs Department for financial support, and Dr Beatriz Villanueva for helpful comments on this manuscript.

\section{REFERENCES}

[1] Baker R.L., Watson T.G., Bisset S.A., Vlassof A., Douch P.G.C., Breeding sheep in New Zealand for resistance to internal parasites: research results and commercial application, in: Gray G.D. and Woolaston R.R. (Eds.), Australian Wool Cooperation, Melbourne, 1991, pp. 19-32.

[2] Balic A., Bowles V.M., Meeusen E.N., The immunobiology of gastrointestinal nematode infections in ruminants, Adv. Parasitol. 45 (2000) 181-241.

[3] Bishop S.C., Stear M.J., Modelling responses to selection for gastro-intestinal parasites in sheep, Anim. Sci. 64 (1997) 469-478.

[4] Bishop S.C., Stear M.J., Genetic and epidemiological relationships between productivity and disease resistance: gastro-intestinal parasite infection in growing lambs, Anim. Sci. 69 (1999) 515-524.

[5] Bishop S.C., Stear M.J., Modeling of host genetics and resistance to infectious diseases: understanding and controlling nematode infections, Vet. Parasitol. 115 (2003) 147-166.

[6] Bishop S.C., Bairden K., McKellar Q.A., Park M., Stear M.J., Genetic parameters for faecal egg count following mixed, natural, predominantly Ostertagtia 
circumcincta infection and relationships with live weight in young lambs, Anim. Sci. 63 (1996) 423-428.

[7] Bisset S.A., Vlassof A., Morris C.A., Sourthey B.R., Baker R.L., Parker A.G.H., Heritability of and genetic correlations among faecal egg counts and productivity traits in Romney sheep, New Zeal. J. Agric. Res. 35 (1992) 51-58.

[8] Coop R.L., Kyriazakis I., Nutrition-parasite interaction, Vet. Parasitol. 84 (1999) 187-204.

[9] Coop R.L., Graham R.B., Jackson F., Wright S.E., Angus K.W., Effect of experimental Ostertagia circumcincta infection on the performance of grazing lambs, Res. Vet. Sci. 38 (1985) 282-287.

[10] Davies G., Investigating genetic aspects of the variation in the host response to gastrointestinal parasites in sheep, Ph.D. thesis, Faculty of Veterinary Medicine, University of Glasgow, 2006.

[11] Davies G., Stear M.J., Bishop S.C., Genetic relationships between indicator traits and nematode parasite infection levels in 6 month old lambs, Anim. Sci. 80 (2005) 143-150.

[12] Emmans G.C., Effective energy: a concept of energy utilization applied across species, Br. J. Nutr. 71 (1994) 801-821.

[13] Falconer D.S., Mackay T.F.C., Introduction to quantitative genetics, 4th edn., Longman, UK, 1996.

[14] Gasbarre L.C., Miller J.E., Genetics of Helminth Resistance, in: Axford R.F.E., Bishop S.C., Nicholas F.W. and Owen J.B. (Eds.), Breeding for disease resistance in farm animals, CAB International, Wallingford, 2000, pp. 129-152.

[15] Goddard M.E., Beilharz R.G., Natural selection and animal breeding, Proc. 3rd Int. Congr., 1977, S.A.B.R.A.O., Animal Breeding Papers 4.19-4.21.

[16] Kyriazakis I., Tolkamp B.J., Hutchings M.R., Towards a functional explanation for the occurrence of anorexia during parasitic infections, Anim. Behav. 56 (1998) 265-274.

[17] McEwan J.C., Mason P., Baker R.L., Clarke J.N., Hickey S.M., Turner K., Effect of selection for productivity traits on internal parasite resistance in sheep, Proc. New Zeal. Soc. An. 52 (1992) 53-56.

[18] McEwan J.C., Dodds K.G., Greer G.J., Bain W.E., Duncan S.J., Wheeler R., Knowler K.J., Rid P.J., Green R.S., Douch P.G.C., Genetic estimates for parasite resistance traits in sheep and their correlations with production traits, New Zeal. J. Zool. 22 (1995) 177.

[19] Meeusen E.N.T., Balic A., Bowles V., Cells, cytokines and other molecules associated with rejection to gastrointestinal nematode parasites, Vet. Immunol. Immunopath. 108 (2005) 121-125.

[20] Nasholm A., Danell O., Genetic relationships of lamb weight, maternal ability, and mature ewe weight in Swedish finewool sheep, J. Anim. Sci. 74 (1996) 329 339.

[21] Rauw W.M., Kanis E., Noordhuizen-Stassen E.N., Grommers F.J., Undesirable side effects of selection for high production efficiency in farm animals: a review, Livest. Prod. Sci. 56 (1998) 15-33. 
[22] Rauw W.M., Luiiting P., Beilharz R.G., Verstegen M.W.A., Vangen O., Selection for litter size and its consequences for the allocation of food resources: a concept and its implications illustrated by mice selection experiments, Livest. Prod. Sci. 60 (1999) 329-341.

[23] Rauw W.M., Knap P.W., Gomez-Raya L., Varona L., Noguera J.L., Reallocation of body resources in lactating mice highly selected for litter size, J. Anim. Sci. 81 (2003) 939-944.

[24] Rendel J.M., Correlation between the number of scutellar and abdominal bristles in Drosophila melanogaster, Genetics 48 (1993) 391-408.

[25] Sangster N.C., Anthelmintic resistance: past, present and future, Int. J. Parasitol. 29 (1999) 115-124.

[26] Vagenas D., Bishop S.C., Kyriazakis I., A model to account for the consequences of host nutrition on the outcome of gastrointestinal parasitism in sheep: logic and concepts, Parasitol. 134 (2007a) 1263-1277.

[27] Vagenas D., Bishop S.C., Kyriazakis I., A model to account for the consequences of host nutrition on the outcome of gastrointestinal parasitism in sheep: model evaluation, Parasitol. 134 (2007b) 1279-1289.

[28] Vagenas D., Doeschl-Wilson A.B., Bishop S.C., Kyriazakis I., Exploration of the effects of host genotype and nutrition on the genetic parameters of lambs challenged with gastrointestinal parasites, Int. J. Parasitol. 37 (2007c) 1617-1630.

[29] van der Waaij E.H., A resource allocation model describing the consequences of artificial selection under metabolic stress, J. Anim. Sci. 82 (2004) 973-981.

[30] Waller P.J., Nematode parasite control of livestock in the tropics / subtropics: the need for novel approaches, Int. J. Parasitol. 27 (1997) 1193-1201. 


\section{APPENDIX 1: MODEL EQUATIONS FOR THE PARAMETERS ASSUMED TO EXHIBIT GENETIC VARIATION}

\section{GROWTH}

The model of Vagenas et al. [28] requires as an input the initial empty body weight $\left(\mathrm{EBW}_{0}\right)$ of each animal. Growth is driven by body protein and lipid retention; their expected values are estimated as:

$$
\begin{aligned}
& \mathrm{dP} / \mathrm{d} t=\mathrm{P} \times \mathrm{B} \times \ln \left(\mathrm{P}_{\text {mat }} / \mathrm{P}\right) \\
& \mathrm{dL} / \mathrm{d} t=\mathrm{L} \times \mathrm{B} \times \ln \left(\mathrm{L}_{\text {mat }} / \mathrm{L}\right)
\end{aligned}
$$

where: $\mathrm{dP} / \mathrm{d} t=$ expected instantaneous protein retention, $\mathrm{dL} / \mathrm{d} t=$ expected instantaneous lipid retention, $\mathrm{P}_{\mathrm{mat}}=$ expected body protein mass at maturity, $\mathrm{P}=$ current body protein mass, $\mathrm{L}_{\mathrm{mat}}=$ expected body lipid mass at maturity, $\mathrm{L}=$ current body lipid mass, $\mathrm{B}=$ determinant of the rate of tissue mass retention.

Differences in empty body weight at the start of the simulation period together with differences in the parameters $\mathrm{P}_{\text {mat }}$ and $\mathrm{L}_{\text {mat }}$, imply growth rate and final size differences between animals [16].

Estimates of the other constituents of body weight, such as water, minerals and wool, are derived from body protein and lipid retentions as described in Vagenas et al. [28].

\section{MAINTENANCE}

Body maintenance comprises the maintenance requirements for protein $\left(\mathrm{P}_{\text {maint }}, \mathrm{kg} \cdot\right.$ day $\left.^{-1}\right)$ and metabolisable energy $\left(\mathrm{ME}_{\text {maint }}, \mathrm{MJ} \mathrm{EE} \cdot \mathrm{day}^{-1}\right)$ :

$$
\begin{gathered}
\mathrm{P}_{\text {maint }}=\mathrm{p}_{\text {maint }} \times \mathrm{P} / \mathrm{P}_{\text {mat }}^{0.27} \\
\mathrm{ME}_{\text {maint }}=\mathrm{e}_{\text {maint }} \times \mathrm{P} / \mathrm{P}_{\text {mat }}^{0.27}
\end{gathered}
$$

where: $\mathrm{p}_{\text {maint }}=$ constant associated with protein for maintenance requirements, $\mathrm{e}_{\text {maint }}=$ constant associated with energy for maintenance requirements. Both constants are assumed to be under genetic control [16]. 


\section{RESISTANCE TO GASTRO-INTESTINAL PARASITISM}

The model assumes that observed variation in worm burden and faecal egg counts is caused by variation in the underlying immune response, represented by host controlled traits of establishment (E), fecundity (F) and mortality (M), which are described by the functions

$$
\begin{gathered}
\mathrm{E}=\left(\varepsilon_{\max } \cdot \mathrm{e}^{-\mathrm{K}_{\mathrm{E}} \cdot\left(\frac{\mathrm{PAC}_{\mathrm{Imm}}}{\mathrm{PRQ} m}\right) \cdot \sum_{t} \mathrm{LI}^{*}}\right)+\varepsilon_{\min } \\
\mathrm{M}=\left(\frac{\mu_{\max } \cdot\left(\mathrm{PAC}_{\mathrm{Imm}} \cdot \sum_{t} \mathrm{LI}^{*}\right)^{2}}{\left(\mathrm{PRQ}_{\mathrm{Imm}} \cdot \mathrm{K}_{\mathrm{M}}\right)^{2}+\left(\mathrm{PAC}_{\mathrm{Imm}} \cdot \sum_{t} \mathrm{LI}^{*}\right)^{2}}\right)+\mu_{\min } \\
\mathrm{F}=\left(\frac{\mathrm{F}_{\max } \cdot\left(\mathrm{K}_{\mathrm{F}} \cdot \mathrm{PRQ}_{\mathrm{Imm}}\right)^{2}}{\left(\mathrm{~K}_{\mathrm{F}} \cdot \mathrm{PRQ}_{\mathrm{Imm}}\right)^{2}+\left(\mathrm{PAC}_{\mathrm{Imm}} \cdot \sum_{t} \mathrm{LI}^{*}\right)^{2}}\right)+\mathrm{F}_{\min }
\end{gathered}
$$

where: $\varepsilon_{\max }, \mu_{\max }, F_{\max }=$ maximum establishment, mortality and fecundity rates respectively, $\varepsilon_{\min }, \mu_{\min }, \mathrm{F}_{\min }=$ minimum establishment, mortality and fecundity rates respectively, $\sum_{t} \mathrm{LI}^{*}=$ scaled cumulative larval intake (used to create an asymptotic relationship between cumulative larval intake and the three immunological traits), $\mathrm{PAC}_{\mathrm{Imm}}=$ protein allocated to immunity, $\mathrm{PRQ}_{\mathrm{Imm}}=$ protein requirement for immunity. The parameters $\mathrm{K}_{\mathrm{E}}, \mathrm{K}_{\mathrm{M}}, \mathrm{K}_{\mathrm{F}}$ are the ratedetermining parameter values associated with establishment, mortality and fecundity, respectively. 